\title{
OS ESPAÇOS DOS BEBÊS NA CRECHE: O QUE DIZEM OS DOCUMENTOS DO MINISTÉRIO DA EDUCAÇÃO
}

\author{
Giseli Alcassas Masson ${ }^{\mathrm{i}}$ \\ Jarina Rodrigues Fernandes ${ }^{\text {ii }}$
}

\begin{abstract}
RESUMO: O objetivo do presente artigo é apresentar um levantamento sobre o que dizem os documentos oficiais brasileiros do Ministério da Educação (MEC), a respeito da temática dos espaços dos bebês na creche. Para tanto, foi realizada pesquisa documental no sítio oficial do MEC, a partir de aportes metodológicos da pesquisa bibliográfica e da análise de conteúdo. Como resultados, identificou-se que todos os nove documentos analisados fazem referência aos espaços para a educação infantil como um todo (de 0 a 5 anos) e cinco deles fazem referências especificamente aos espaços dos bebês (de 0 a 1 ano e meio). Estes resultados demonstram com relação à temática estudada, que a categoria bebê vem ganhando expressividade nos documentos que orientam a educação nacional.
\end{abstract}

Palavras-Chave: espaços; bebês; creche.

\section{ESPACIOS PARA BEBÉS EN LA GUARDERÍA INFANTIL: QUÉ DICEN LOS DOCUMENTOS DE MINISTERIO DE EDUCACIÓN}

RESUMEN: El objetivo de este artículo es presentar un levantamiento de lo que dicen los documentos oficiales de Ministerio de Educación de Brasil (MEC), con respecto al tema de los espacios para bebés en la guardería infantil. Para ello, se realizó una investigación documental en el sitio web oficial de MEC, basada en contribuciones metodológicas de la investigación bibliográfica y del análisis de contenido. Como resultado, se encontró que los nueve documentos analizados se refieren a los espacios para la educación de la primera infancia en su conjunto (de 0 a 5 años) y cinco de ellos se refieren específicamente a los espacios de los bebés (de 0 a 1 año y medio). Estos resultados demuestran, relativamente al tema estudiado, que la categoría bebé ha ido ganando expresividad en los documentos que guían la educación nacional.

Palabras-Clave: espacios; bebés; guardería infantil.

\section{INTRODUÇÃO}

O objetivo do presente artigo é apresentar um levantamento sobre o que dizem os documentos oficiais brasileiros do Ministério da Educação (MEC), a respeito da temática dos espaços dos bebê $s^{i i i}$ no contexto coletivo de creche. 
Com a Declaração dos Direitos da Criança de Genebra em 1924, a Declaração Universal dos Direitos Humanos de 1948 e a Declaração Universal dos Direitos da Criança e do Adolescente em 1959, as crianças passaram a ser reconhecidas no mundo como cidadãs e portadoras de direitos. No Brasil, desde a Constituição Federal Brasileira (CF) (BRASIL, 1988) e a Lei de Diretrizes e Bases da Educação Nacional (LDB) (BRASIL, 1996) abriram-se as portas para maior atenção à educação infantil (EI), seja em creches ou pré-escolas.

Quanto aos espaços dos bebês na creche, embora haja pesquisas brasileiras recentes no campo da Educação que tenham se debruçado sobre a temática e as especificidades dos bebês neste contexto de vida coletiva (BARBOSA; RICHTER, 2009; SINGULANI, 2009; BARBOSA, 2010; RAMOS, 2010; GOBBATO, 2011; TUSSI, 2011; ALVES, 2013; HORN, 2015; BRASIL, 2016; SCHORN, 2018; SILVA, 2018), Barbosa e Richter (2009) já constatavam que as que envolvem bebês e crianças pequenas ainda aparecem em número muito menor do que as que focalizam as crianças de quatro e cinco anos, indicando a necessidade de incremento de estudos voltados às questões pedagógicas e curriculares.

Nessa perspectiva, é relevante tecer um panorama sobre o que dizem os documentos oficiais do MEC voltados à EI sobre os espaços dos bebês, dada a abrangência nacional de tais documentos e a possibilidade de mapear indicações e orientações referentes à temática, tendo em vista a qualidade do atendimento, a organização de práticas pedagógicas e curriculares, a formação inicial e continuada dos educadores e, sobretudo, a aprendizagem e o desenvolvimento dos bebês nessas instituições.

Diante do exposto, a primeira seção do artigo, apresenta contribuições de autores contemporâneos que ajudam a pensar nos espaços dos bebês na creche. A segunda seção mostra o percurso metodológico trilhado para a realização da pesquisa documental. Por fim, a terceira seção expõe uma análise acerca da presença/ausência de referência aos bebês nos documentos oficiais do MEC voltados à EI e do que dizem sobre os espaços dos bebês na creche, seguida pelas considerações finais.

\section{AS CRIANÇAS, OS BEBÊS E O ESPAÇO}

Abordagens teóricas de matrizes diversas e diferentes áreas de conhecimento têm se debruçado sobre a temática das crianças, dos bebês e do espaço. Nesse percurso, o 
reconhecimento das crianças como atores sociais ativos tem sido uma das ênfases presentes na literatura contemporânea sobre a infância:

A criança é um ser humano também do hoje que não pode ser limitado ao amanhã, precisa ser compreendida a partir de si mesma e do seu próprio contexto. Representa um sujeito social, que não está passivo em seu processo de socialização, faz história e produz cultura. (LIMA; MOREIRA; LIMA, 2014, p. 99-100)

A partir de estudos da Sociologia da infância (SARMENTO, 2001, 2004; CORSARO, 2011), as crianças são compreendidas como sujeitos que operam transformações na cultura, não simplesmente reproduzem as existentes, sendo preciso enxergá-las como atores sociais e considerar as suas culturas, ouvi-las, investir e valorizar a participação delas nas atividades desenvolvidas. Sarmento (2004) fala em culturas, no plural, referindo-se à capacidade que as crianças têm de atuarem como atores sociais críticos, distinguindo-se dos modos de agir e significar dos adultos por compreender que possuem seus próprios modos para tal. Também assumindo a criança enquanto sujeito que produz cultura, Corsaro (2011, p 32) fala em cultura de pares, como "conjunto estável de atividades ou rotinas, artefatos, valores e interesses que as crianças produzem e compartilham na interação com seus pares".

A partir desse enfoque, Sarmento (2001) compreende que a infância é uma construção social e que os papéis sociais desenvolvidos pelas crianças são historicamente produzidos, são objetos de variação e de mudança em função das variáveis sociais. Ainda sob esta perspectiva, as crianças são vistas como sujeitos competentes que têm direito ao conhecimento e que devem estar inseridas em uma cultura e participar dela ativamente. Devido a isso, é necessário pensar em um espaço onde as crianças sejam reconhecidas como sujeitos ativos que têm o direito de participar e de intervir no que acontece ao seu redor, recriando e reelaborando o mundo, sendo respeitadas e compreendidas como produto e produtoras da história e da cultura do mundo em que estão inseridas. Alinhadas a essas concepções encontram-se estudos sobre os bebês e os espaços da creche, tais como as pesquisas de Ramos (2010), Gobatto (2011), Silva (2018) e Schorn (2018).

Ainda no tocante à questão dos bebês, dos espaços e da cultura, outra vertente que frequentemente encontra-se presente é a Psicologia Histórico-Cultural que, na perspectiva vigotskyana, destaca

[...] a importância da interferência intencional do adulto - do planejamento competente do educador - e também a importância de atividades com grupos de crianças de diferentes idades e níveis de desenvolvimento, onde quem sabe ensina quem não sabe. 
O educador deve, portanto, intervir, provocando avanços que de forma espontânea não ocorreriam. (MELLO, 2004, p. 144)

Sob esse enfoque, a cultura é compreendida como conhecimento social e historicamente construído, sendo que o papel da escola é atuar para que os bebês e as crianças apropriem-se da cultura na qual estão inseridos, tendo em vista que a aprendizagem mediada impulsiona o desenvolvimento. A partir deste aporte teórico, os bebês e as crianças não têm condições de decifrar por elas mesmas o que a cultura humana conquistou, por este motivo, necessitam da ajuda dos educadores, sejam eles professores, ou parceiros mais experientes, sobretudo na organização dos espaços, que também se tornam mediadores da aprendizagem. Fundamentadas nessa concepção, encontram-se as pesquisas sobre os bebês e os espaços da creche, tais como a de Singulani (2009), Tussi (2011), Alves (2013) e Brasil (2016).

Outras áreas também têm contribuído para pensar a questão dos espaços na infância, entre elas, a Arquitetura (LIMA, 1989) e a Geografia Humanística (TUAN, 1983, 2013).

Lima (1989) destaca que os espaços da escola, muitas vezes, são a única oportunidade que as crianças residentes em zonas urbanas têm para vivenciar a curiosidade e a imaginação com relação à natureza, livres da passividade a qual estão submetidas. Baseada na perspectiva foucaultiana, Lima (1989) compreende também que o espaço pode interferir no disciplinamento das crianças e alerta que a escola, por meio dos seus aspectos interiores e exteriores, reflete sua concepção educativa.

Já Tuan (1983, 2013) afirma que entre as pessoas e os ambientes vividos existe um elo afetivo que favorece a identidade e o sentimento de pertencimento. O espaço, que para o autor é somente algo físico e indiferenciado, se transforma em um lugar, na medida em que é dotado de valor. Para o autor, o espaço educacional é um elemento curricular e precisa ser transformado em lugar, pois lugar é referência, proteção e promove a identificação.

Por fim, encontramos abordagens que trazem indicações e proposições advindas da Pedagogia, relativas ao aprimoramento da organização dos espaços na Educação Infantil.

Zabalza (1998) defende que a infância precisa de espaços amplos, diferenciados, com fácil acesso e especializados, onde as crianças possam desenvolver-se integralmente, movimentando-se, interagindo, vivendo e convivendo. Destaca que os espaços devem oferecer diferentes oportunidades para interagir e aprender. Segundo o autor, as aulas convencionais, os espaços indiferenciados, os cenários empobrecidos, dificultam ou até tornam impossível a autonomia e a atenção individual que deve ser dada à cada criança. 
Forneiro (1998), em seu texto A Organização dos Espaços na Educação Infantil, colabora para o aprofundamento da questão no contexto da EI, ao estabelecer uma distinção entre os termos espaço e ambiente. Para a autora, tratam-se de termos intimamente relacionados, contudo, distintos. O termo espaço "refere-se ao espaço físico, ou seja, aos locais para a atividade caracterizados pelos objetos, pelos materiais didáticos, pelo mobiliário e pela decoração"; o termo ambiente "refere-se ao conjunto do espaço físico e às relações que se estabelecem no mesmo (os afetos, as relações interpessoais entre as crianças, entre crianças e adultos, entre crianças e sociedade em conjunto)" (FORNEIRO, 1998, p. 232-233).

\begin{abstract}
O termo ambiente é procedente do latim e faz referência "ao que cerca ou envolve". Também pode ter a acepção de "circunstâncias que cercam as pessoas ou as coisas". De um modo mais amplo, poderíamos definir o ambiente como um todo indissociável de objetos, odores, formas, cores, sons e pessoas que habitam e se relacionam dentro de uma estrutura física determinada que contém tudo e que, ao mesmo tempo, é contida por todos esses elementos que pulsam dentro dele como se tivessem vida. Por isso, dizemos que o ambiente "fala", transmite-nos sensações, evoca recordações, passa-nos segurança ou inquietação, mas nunca nos deixa indiferentes. (FORNEIRO, 1998, p. 233, grifo nosso)
\end{abstract}

Para esta autora, o espaço escolar é um ambiente de aprendizagem, e sob seu ponto de vista, esse ambiente é uma estrutura que possui quatro dimensões: i) dimensão física: aspecto físico e material do ambiente, com suas condições estruturais, seus objetos e sua organização; ii) dimensão funcional: forma de utilização dos espaços (autonomamente pela criança ou com a orientação do professor), polivalência (várias funções) e tipo de atividade a qual se destina (cantos); iii) dimensão temporal: refere-se ao tempo, momentos em que os diferentes espaços serão utilizados, sendo que a organização do espaço precisa ser coerente com a organização do tempo, e o inverso também é válido; iv) dimensão relacional: refere-se às relações que são estabelecidas: modo de se ter acesso ao espaço, estabelecimento das normas, agrupamentos para realização das atividades e participação do professor.

Embora todos os elementos que compõem o ambiente e que reunimos nessas quatro dimensões possam existir independentemente, cada um por si, o ambiente somente existe na inter-relação de todos eles. Não possui uma existência material, como o espaço físico. $\mathrm{O}$ ambiente existe à medida que os elementos que o compõem interagem entre si. Por isso, cada pessoa o percebe de uma maneira diferente. (FORNEIRO, 1998, p. 235)

Para a autora, o espaço é um elemento curricular que precisou passar por três etapas para se constituir como o compreendemos na contemporaneidade: em uma primeira etapa o espaço era visto somente como um lugar onde se ensina; na segunda, como um elemento facilitador e, somente na terceira, juntamente com os elementos que o compõem, passa então a ser 


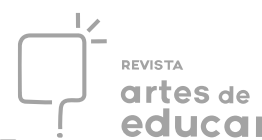

compreendido como um fator de aprendizagem, como recurso educativo. Nessa perspectiva, para a autora, os elementos do espaço, tais como o mobiliário, os materiais didáticos e a decoração tornam-se componentes curriculares.

Campos de Carvalho e Rubiano (2010), em seu texto Organização do espaço em instituições pré-escolares, têm como objetivo refletir sobre a maneira como os educadores podem organizar seus ambientes em função dos objetivos que pretendem atingir fazendo com que reconheçam que os aspectos físicos dos ambientes têm impacto sobre o comportamento de quem vai fazer uso deles. Para tanto, focalizam as funções da organização do espaço, do ambiente, as concepções de desenvolvimento e os estudos sobre arranjos espaciais, por compreenderem que a maneira como os equipamentos e o mobiliário estão organizados nos espaços favorecem ou não a ocorrência de interações.

Já os estudos de Faria (2000), Sitta (2008), Horn (2014), Soares e Flores (2017) e Fochi (2018) trazem também discussões acerca dos espaços externos.

Faria (2000), em estudo publicado anteriormente aos documentos oficiais analisados na presente pesquisa, indica que as instituições de EI deveriam organizar o espaço de modo que fossem priorizados os objetivos pedagógicos e contemplada a diversidade cultural. Quanto à organização dos ambientes, a autora destaca ainda a pertinência de atividades com água, terra, fogo e ar; sombra para os dias quentes; coberturas para dias chuvosos, espaços frescos no verão e aquecidos no inverno; ambiente bem projetado, agradável, bonito, desafiador; iluminado, ventilado, acolhedor, que agreguem turmas homogêneas e também mistas; espaços onde as crianças possam se dividir em pequenos grupos e escolher com o que desejam brincar, espaços onde exista interação; onde tudo esteja ao alcance das crianças e a movimentação seja livre.

Já o foco de Sitta (2008) é o papel do espaço como componente estruturante da realidade social, uma vez que a organização do espaço escolar tem se constituído, quase sempre, em um grande obstáculo no respeito aos direitos de brincar das crianças. Para Sitta (2008, p.114), é imprescindível considerar que "a estrutura física, os tipos de brincadeiras e a mediação do professor exercem, juntos, influência no espaço, ao mesmo tempo que esse espaço exerce influência neles", em um movimento intrínseco, recíproco e contínuo.

Nessa perspectiva, Horn (2004) investiga o uso dos espaços externos nas escolas brasileiras e identifica a realidade de confinamento aos espaços internos dos prédios, com predominância para as atividades que envolvem lápis e papel, onde as crianças estão sentadas em mesas, com a privação do sol e raros momentos em que elas podem subir em árvores, brincar com água, sujar-se com areia, etc.

Revista Interinstitucional Artes de Educar. Rio de Janeiro, V. 6, N.2- pág. 556-577 maio-agosto de 2020: "Bebês e crianças: cultura, linguagem e políticas" 
Fochi (2018) focaliza também, em sua pesquisa, a pertinência do trabalho com o espaço externo, do mesmo modo que o espaço interno das escolas de educação infantil, pois também se mostra como um potente ambiente de aprendizagem às crianças.

Isso torna-se possível a partir do planejamento e olhar atento do educador, pois brincar ao ar livre em contato com a natureza é dar tempo à criança para ela se conectar a si mesma, ter a oportunidade da experiência, do contato com elementos naturais, de imaginar, de explorar. Nesse sentido, os espaços são os provocadores dessas ações não demandando da mediação direta do adulto já que o próprio espaço, quando satisfatório, pode fazer isso. (Fochi, 2018, p. 54)

Para que as crianças tenham opções de escolher livremente com o que brincar, apoiadas em Brown (2006), Soares e Flores (2017) defendem que é necessário disponibilizar vários espaços no ambiente externo. Nesses espaços, os adultos colocam-se em um papel apenas de supervisão das brincadeiras, interferindo em casos de dano físico ou violência, deixando as crianças terem mais liberdade e autonomia para fazerem suas escolhas, considerando que "para muitas crianças, portanto, as áreas externas da escola constituem o único ambiente social para brincar em que elas podem interagir em grandes grupos e fora da vigilância imediata dos adultos" (BROWN, 2006, p. 64).

Por fim, Tonucci (2005) faz uma reflexão acerca da preocupação que os adultos têm a respeito da segurança das crianças quando estão nos espaços externos. Defende que a segurança é necessária e importante, porém não deve privá-las da experimentação e vivência de novos desafios. Segundo o autor, na busca de dominar e superar o que é novo, o risco é um elemento fundamental para o crescimento e o desenvolvimento. Ao ofertar materiais e equipamentos devemos ter a confiança que

a criança não é um aspirante a suicida, como parecem acreditar os adultos, mas ela é capaz de enfrentar aquele perigo e o faz com grande sentido de responsabilidade e prudência, adotando comportamentos adequados para enfrentar com sucesso a dificuldade. (TONUCCI, 2005, p. 72)

Nessa perspectiva, vale considerar a contribuição de Barros (2018, p. 42) ao destacar que "os pátios e toda a escola podem ser espaços de alegria”, espaços capazes de instigar descobertas e experimentações e permitir a construção de conhecimento e desenvolvimento humano, espaços privilegiados que podem fazer da escola um lugar para se viver a infância.

\section{PERCURSO METODOLÓGICO}

Revista Interinstitucional Artes de Educar. Rio de Janeiro, V. 6, N.2- pág. 556-577 maio-agosto de 2020: "Bebês e crianças: cultura, linguagem e políticas" 
A pesquisa realizada é de natureza documental, visto que as fontes consultadas são os documentos oficiais disponibilizados no sítio do MEC. Segundo Sá-Silva, Almeida e Guindani (2009, p. 2), o uso de documentos deve ser valorizado pela possibilidade de reconstrução de uma trajetória, para "o entendimento de objetos cuja compreensão necessita de contextualização histórica e sociocultural". Neste caso, busca-se identificar como a questão dos espaços dos bebês na creche vem sendo abordada pelos referidos documentos na história recente do país, no período pós LDB (BRASIL, 1996).

Para percorrer a etapa de seleção dos dados o estudo apoiou-se em Salvador (1986) e Lima e Mioto (2007) que trazem orientações para a realização de pesquisas bibliográficas. Ainda que se trate de uma pesquisa documental (e não bibliográfica, voltada a produções científicas), compartilha-se do entendimento que os procedimentos indicados pelos autores supracitados, eram pertinentes à investigação a ser realizada.

Salvador (1986) identifica cinco fases de leitura diferenciadas para cada momento da pesquisa, sendo elas: i) Leitura de reconhecimento ou prévia; ii) Leitura exploratória ou préleitura; iii) Leitura seletiva; iv) Leitura reflexiva ou crítica e v) Leitura interpretativa. As três primeiras fases foram percorridas para seleção dos documentos no sítio oficial do MEC. A Leitura de reconhecimento ou prévia permitiu um primeiro contato com os documentos, de forma rápida, a fim de percorrer os títulos, índices, sumários, procurando pelos assuntos de interesse, confirmando se naquele texto os bebês, as crianças de 0 a 3 anos, a temática dos espaços na Educação Infantil e dos espaços dos bebês na creche eram contemplados. A Leitura exploratória ou pré-leitura permitiu constatar se o texto escolhido previamente correspondia ao que havia prometido. Por meio da Leitura seletiva, buscou-se focalizar as informações que eram pertinentes à questão da pesquisa, com seleção de excertos referentes ao espaço dos bebês na creche (SALVADOR, 1986, p. 103).

É relevante destacar que, inspiradas em aportes e procedimentos da análise de conteúdo indicados por Bardin (2007), foi utilizada nessa etapa inicial de coleta de dados, a contagem frequencial dos termos bebê ou bebês, da expressão 0 a 3 anos, (ao perceber que alguns documentos não chegavam a destacar o termo bebês, mas já se preocupavam em separar indicações para as crianças menores da EI) e do termo espaço. Em todos os documentos, exceto em Brinquedos e Brincadeiras de Creches - Manual de Orientação Pedagógica (BRASIL, 2012a), a busca foi facilitada pela ferramenta destinada a localizar palavra, disponível no leitor de pdf. No caso específico do material mencionado (BRASIL, 2012a), a contagem frequencial 


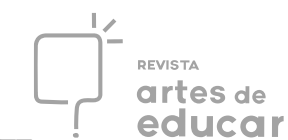

foi feita manualmente, pela impossibilidade de utilizar a ferramenta citada, dada a configuração do documento que impediu buscas com a referida ferramenta.

Depois de localizar e selecionar o material almejado, passou-se então à Leitura reflexiva ou crítica a respeito do que cada documento afirmava sobre os espaços dos bebês na creche. Foi investigado se, próximo às ocorrências do termo bebê( $(s)$ e do termo espaço, havia menções específicas ao espaço dos bebês na creche. Por fim, a Leitura interpretativa, voltada a compreender o que dizem os documentos sobre a temática em questão, se fez à luz de autores que compõem o aporte teórico da pesquisa. Por fim, foi elaborada uma síntese integradora (SALVADOR, 1986; LIMA; MIOTO, 2007), que buscou compreender as posições defendidas e atender aos objetivos da investigação. A síntese encontra-se na seção destinada à análise dos dados.

\section{O ESPAÇO DOS BEBÊS NA CRECHE: O QUE DIZEM OS DOCUMENTOS OFICIAIS DO MEC}

As três primeiras etapas de leitura - de reconhecimento, exploratória e seletiva conduziram à identificação de nove documentos oficiais do Ministério da Educação voltados à EI, a saber: Política Nacional de Educação Infantil: Pelo Direito das Crianças de 0 a 6 anos à educação ${ }^{i v}$ (BRASIL, 2006a); Parâmetros Nacionais para a Qualidade da Educação Infantil Volume 1 (BRASIL, 2006b) e Volume 2 (BRASIL, 2006c); Parâmetros Básicos de Infraestrutura para Instituições de Educação Infantil (BRASIL, 2006d); Diretrizes Curriculares Nacionais para a Educação Infantil (BRASIL, 2009a); Critérios para atendimento em creches que respeitem os direitos fundamentais das crianças (BRASIL, 2009b); Brinquedos e Brincadeiras de Creches - Manual de Orientação Pedagógica (2012a); Educação Infantil: subsídios para a construção de uma sistemática de avaliação (BRASIL, 2012b) e Base Nacional Comum Curricular (BRASIL, 2018).

Ao buscar excertos que fizessem menção aos espaços dos bebês na creche, chamou a atenção que nem todos os documentos referem-se especificamente a bebês. Outra constatação é que ao se referirem à questão do espaço, a maioria dos documentos traz orientações para toda a EI, as quais não deixam de ser significativas também para as crianças menores, contudo, não se constituem, especificamente, indicações para os espaços dos bebês na creche, conforme dados compilados no Quadro 1:

Revista Interinstitucional Artes de Educar. Rio de Janeiro, V. 6, N.2- pág. 556-577 maio-agosto de 2020: "Bebês e crianças: cultura, linguagem e políticas"

DOI: $10.12957 /$ riae.2020.45958 

de 2020: "Bebês e crianças: cultura, linguagem e políticas" 


\section{Quadro 1: Referências a Bebês, Espaços na EI e Espaços dos bebês na creche em documentos oficiais do MEC}

\begin{tabular}{|c|c|c|c|c|}
\hline Ano & & \multicolumn{3}{|c|}{ Referências a } \\
\hline BRASIL & Documentos do MEC analisados & $\begin{array}{c}\text { Bebê(s) } \\
(0 \text { a } 18 \text { meses })\end{array}$ & $\begin{array}{l}\text { Espaço(s) na } \\
\text { EI }\end{array}$ & $\begin{array}{c}\text { Espaços dos } \\
\text { bebês na creche }\end{array}$ \\
\hline $2006 a$ & $\begin{array}{l}\text { Política Nacional de Educação Infantil: } \\
\text { Pelo Direito das Crianças de } 0 \text { a } 6 \text { anos à } \\
\text { educação }\end{array}$ & 0 & 4 & 0 \\
\hline $2006 b$ & $\begin{array}{l}\text { Parâmetros Nacionais para a Qualidade da } \\
\text { Educação Infantil - Volume } 1\end{array}$ & 7 & 6 & 2 \\
\hline $2006 c$ & $\begin{array}{l}\text { Parâmetros Nacionais para a Qualidade da } \\
\text { Educação Infantil - Volume } 2\end{array}$ & 12 & 9 & 1 \\
\hline $2006 \mathrm{~d}$ & $\begin{array}{l}\text { Parâmetros Básicos de Infraestrutura para } \\
\text { Instituições de Educação Infantil }\end{array}$ & 0 & 44 & 0 \\
\hline $2009 a$ & $\begin{array}{l}\text { Diretrizes Curriculares Nacionais para a } \\
\text { Educação Infantil (DCNEI) }\end{array}$ & 0 & 3 & 0 \\
\hline $2009 b$ & $\begin{array}{l}\text { Critérios para atendimento em creches que } \\
\text { respeitem os direitos fundamentais das } \\
\text { crianças }\end{array}$ & 10 & 23 & 3 \\
\hline $2012 \mathrm{a}$ & $\begin{array}{l}\text { Brinquedos e Brincadeiras de Creches - } \\
\text { Manual de Orientação Pedagógica }\end{array}$ & 190 & 93 & 41 \\
\hline $2012 b$ & $\begin{array}{l}\text { Educação Infantil: subsídios para a } \\
\text { construção de uma sistemática de } \\
\text { avaliação }\end{array}$ & 1 & 30 & 0 \\
\hline 2018 & Base Nacional Comum Curricular & 13 & 10 & 2 \\
\hline
\end{tabular}

Fonte: Quadro organizado pelas autoras a partir de documentos oficiais disponíveis no sítio do MEC

O documento Política Nacional de Educação Infantil: Pelo Direito das Crianças de 0 a 6 anos à educação (BRASIL, 2006a) se destaca pela sua contribuição no processo democrático de implementação de políticas públicas para esta etapa da educação, ao trazer diretrizes, objetivos, metas e estratégias para a área, incluindo, no tocante ao foco do artigo, indicações referentes à organização do espaço na EI. Embora esse documento não apresente o termo bebê( $(s)$, de forma específica, seu título indica que o texto refere-se às crianças de 0 a 6 anos, portanto, os bebês estão contemplados, mas não mencionados em suas especificidades. No tocante ao espaço para crianças de 0 a 6 anos, o documento faz menção dentre os objetivos da Política Nacional da Educação Infantil, o de "garantir espaços físicos, equipamentos, brinquedos e materiais adequados nas instituições de EI, considerando as necessidades educacionais especiais e a 


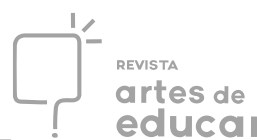

diversidade cultural" (BRASIL, 2006a, p. 19). Dentre suas metas está a de garantir no espaço interno, iluminação, “insolação, ventilação, visão para o espaço externo, rede elétrica e segurança, água potável, esgotamento sanitário [...]” (BRASIL, 2006a, p. 21). Podemos perceber, desse modo, uma ênfase na dimensão física dos espaços (FORNEIRO, 1998), com destaque a aspectos materiais e estruturais dos espaços para as crianças de 0 a 6 anos.

Os Parâmetros Nacionais para a Qualidade da Educação Infantil publicados em dois volumes, apresenta no Volume 1 (BRASIL, 2006a) aspectos introdutórios, a concepção de criança e de pedagogia da EI, a trajetória da qualidade nesta etapa, as tendências identificadas nas pesquisas brasileiras e em outros países, desdobramentos, consensos e polêmicas. Nesse primeiro volume, o termo bebê( $(s)$ aparece sete vezes e em relação aos espaços dos bebês faz duas referências. A primeira indica que os profissionais de EI precisam estar atentos às necessidades dos bebês interpretando seus desejos e motivações, para que possam decidir sobre o que deverá ser desenvolvido com eles em relação à organização dos espaços, tempos, materiais e agrupamentos, tendo em vista o desenvolvimento e a aprendizagem.

Em uma segunda referência aos espaços dos bebês na creche, destaca que as crianças e os bebês ficam a maior parte do tempo nos espaços internos das instituições escolares, sendo que as estratégias educacionais devem permitir que eles conheçam a natureza, usufruam dela, sintam o vento, brinquem com água e areia, desfrutem do ar livre, etc. As crianças têm direito a espaços, tempos e materiais específicos e precisam ser incentivadas, entre outras coisas: “[...] a movimentar-se em espaços amplos e ao ar livre; [...] ampliar permanentemente conhecimentos a respeito do mundo da natureza e da cultura [...]" (BRASIL, 2006a, p. 19), aspectos que vêm ao encontro do que apresenta Tiriba (2005).

A leitura do documento permite, portanto, identificar uma ênfase ao papel docente na organização dos espaços e materiais articulada à questão da organização do tempo e dos agrupamentos (FORNEIRO, 1998; CAMPOS DE CARVALHO; RUBIANO, 2010), com destaque à questão do direito ao espaço (SITTA, 2008), o que demanda que os bebês possam ter contato com a natureza, ar livre, o que inclui, portanto, espaços amplos (ZABALZA, 1998; FARIA, 2000) e espaços externos (HORN, 2004; SOARES; FLORES, 2017; FOCHI, 2018).

O Volume 2 (BRASIL, 2006c) mostra as competências dos sistemas de ensino, a caracterização das instituições de EI no Brasil e traz os parâmetros nacionais de qualidade para as instituições desta etapa. O termo bebê( $(s)$ aparece doze vezes, sendo que com relação aos espaços dos bebês, é feita somente uma menção no documento, no sentido de assegurar que tanto 
os bebês quanto as demais crianças se movimentem em espaços amplos diariamente, aspecto já salientado no Volume 1.

O documento Parâmetros Básicos de infraestrutura para instituições de Educação Infantil (BRASIL, 2006d) foi publicado no sentido de subsidiar os sistemas de ensino nas adaptações, reformas e construções de espaços de EI, cabendo a cada sistema fazer as adequações à sua realidade, respeitando as características da comunidade na qual a instituição está ou será inserida. Este documento não faz nenhuma menção ao termo bebê( $(s)$, e embora apareçam 44 menções aos espaços na EI como um todo - e os bebês estejam incluídos nessa categoria - nenhuma menção é feita aos espaços dos bebês em específico.

Em 2009, são aprovadas as Diretrizes Curriculares Nacionais para a Educação Infantil (DCNEI) (BRASIL, 2009a) trazendo novos estudos e concepções acerca da criança, da infância, do currículo, da organização dos espaços, tempos e materiais, das brincadeiras e interações, da diversidade cultural, entre outras temáticas. Neste documento o termo bebê( $(s)$ não aparece. São feitas três menções aos espaços para a EI e nenhuma aos espaços para bebês de forma específica.

No documento Critérios para atendimento em creches que respeitem os direitos fundamentais da criança ${ }^{v}$ (BRASIL, 2009b), o termo beb̂e(s) aparece 10 vezes. São feitas 23 menções ao termo espaço considerando toda a faixa etária atendida pela creche, sem distinção de idade. Com relação aos bebês, o documento coloca que sempre que possível eles devem ser levados a um passeio ao ar livre, não devem ser esquecidos nos berços, pois têm o direito de engatinhar, explorar novos ambientes e interagir com seus pares e adultos. Identificamos, portanto que, mais uma vez, aparece a temática do espaço externo (HORN, 2014; FOCHI, 2018; SOARES; FLORES, 2017), do direito ao espaço e o papel docente (SITTA, 2008), bem como ênfase ao que Forneiro (1998) categoriza como dimensão relacional do espaço, com foco na possibilidade de interação dos bebês com outras crianças e adultos à medida que se oportuniza que estejam em espaços diversificados da creche.

O documento Brinquedos e Brincadeiras de Creches - Manual de Orientação Pedagógica (BRASIL, 2012a) foi elaborado pelo Ministério da Educação em parceria com a UNICEF, em colaboração com a Dra. Tizuco Morchida Kishimoto (especialista em brincadeiras) e a Dra. Adriana Freyberger (especialista em espaços para crianças), baseado nas Diretrizes Curriculares Nacionais para a Educação Infantil. Como o documento em questão é todo voltado às faixas etárias a serem atendidas em creches, subdivide-as em bebês de 0 a 18 meses e crianças pequenas de 1 ano e meio a 3 anos e 11 meses. Quanto à utilização da terminologia 0 a 3 anos, 


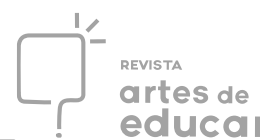

tal qual aparece nos documentos analisados anteriormente, o documento só a apresenta duas vezes, pela precisão em considerar o limite do atendimento da creche, ou seja, até 3 anos e 11 meses. No tocante aos bebês, chama a atenção a presença de duas seções direcionadas inteiramente a eles: uma delas voltada aos Brinquedos, brincadeiras e materiais para bebês $(0$ a 1 ano e meio) e outra à Organização do espaço físico, dos brinquedos e materiais para bebês e crianças pequenas, havendo uma subseção voltada especificamente aos Ambientes para bebês. Neste documento o termo bebê(s) aparece 190 vezes, sendo o documento que mais apresenta as especificidades dos bebês tanto com relação a brinquedos, brincadeiras e materiais quanto à organização dos espaços e ambientes para eles.

Quanto à especificidade dos espaços dos bebês, o documento apresenta que o bebê "ingressa no mundo matemático pelo uso do corpo no espaço, pelas experiências que realiza com os objetos" (BRASIL, 2012a, p. 35, grifo nosso). Os bebês e as crianças pequenas não devem ser submetidos a situações de risco e desconforto, por isso, o projeto de arquitetura do edifício "deve atender às normas de conforto ambiental" (BRASIL, 2012a, p. 40). As experiências do bebê na creche são ampliadas por meio de suas interações com outras crianças, espaços e materiais. Os ambientes externos precisam promover desafios saudáveis aos bebês e crianças pequenas. É preciso planejar ambientes educativos para cada fase de vida do bebê e "selecionar brinquedos e brincadeiras que ampliem suas experiências" (BRASIL, 2012a, p. 63), de modo que possam se movimentar em espaços pensados de forma a atender seus próprios interesses e necessidades.

O documento descreve também alguns detalhes, tais como: "depois que o bebê aprendeu a engatinhar, oferecer novas experiências: na grama, na areia ou subir e descer num pequeno declive" (BRASIL, 2012a, p. 78); o professor pode também organizar o espaço com novos desafios, como estruturas de espuma para subir e descer, túneis com cadeiras, mesas ou caixas de papelão e que o professor deve prever também a segurança do bebê, fechando tomadas, verificando se não há buracos com aberturas cortantes pela sala e nos brinquedos e outros objetos do ambiente. Percebe-se que todas as dimensões do espaço apontadas por Forneiro (1998) aparecem contempladas nos excertos destacados: física, funcional, temporal e relacional. Como se trata de um manual de orientação pedagógica, para além da ênfase na importância na organização e planejamento de ambientes educativos, o documento apresenta orientações com relação aos ambientes para bebês no tocante a cinco segmentos:

i) Entrada e acolhimento: é o espaço 
[...] onde a professora recebe a mãe e a criança antes de entrar na sala de atividades e onde a criança pode brincar com a professora ou com a mãe, fortalecendo vínculos, preparando-se para a separação, acostumando-se à mudança e aprendendo a valorizar a relação trilateral - mãe - filho(a) - professora. É um ambiente silencioso, mas não isolado, pois a transparência da divisória favorece o contato visual com o restante da sala e transmite segurança à mãe, ao ver sua criança ser bem acolhida na instituição. Neste espaço, podem ser apreciados portfólios ou documentação pedagógica com os desenhos, pinturas, esculturas criadas pelas crianças, e oferecidas cadeiras para que os pais possam acompanhar com comodidade, as atividades de seus filhos. (BRASIL, 2012a, p. 112-113)

ii) Sala de atividades e de experiências: com espelhos, piso térmico, tapetes antialérgicos, almofadões, onde os bebês engatinhem e se movimentem, explorando os objetos usando seu corpo e suas habilidades motoras. Com janelas grandes e baixas (indica-se $30 \mathrm{~cm}$ do chão), biombos, cortinas, divisórias baixas e elementos flexíveis que permitam expansão e retraimento da sala.

iii) Espaço do sono: integrado à sala de atividades, mas isolado, de maneira a permitir intimidade e proteção quando necessário. Venezianas e cortinas escuras podem favorecer estes momentos.

iv) Espaço do banho: também integrado, tanto à sala de atividades quanto ao espaço do sono.

v) Solário e jardim sensorial: espaço agradável, de bem-estar, que oferece experiências boas para estar, interagir, brincar e fazer descobertas. Jardim aromático (ervas e plantas), pisos sensoriais, caixas de areia, móbiles, espaços para brincar com água e terra etc.

Ainda nesse documento, com relação aos espaços dos bebês, destaca-se que em alguns casos é negado o direito dos bebês de brincarem nos espaços externos, pela falta de pisos adequados para engatinhar e cantos com sombra, demonstrando consonância com resultados de pesquisas sobre uso de espaços externos na creche (FARIA, 2000; SITTA, 2008; HORN, 2014; BRASIL, 2016; SOARES; FLORES, 2017; FOCHI, 2018).

Já no documento Educação Infantil: Subsídios para a construção de uma sistemática de avaliação (BRASIL, 2012b) o termo bebês aparece somente uma vez, no intuito de dizer que a Formação dos profissionais deve ser garantida contemplando conteúdos referentes a faixa etária de 0 a 5 anos com atenção especial ao trabalho com os bebês. Embora faça 30 menções aos espaços para a EI, o documento não especifica os espaços dos bebês, somente indica a necessidade de adaptação dos espaços considerando a faixa etária de cada criança. 
Por fim, a Base Nacional Comum Curricular (BNCC) (BRASIL, 2018), no tocante à EI, assegura seis direitos de aprendizagem e desenvolvimento aos bebês, crianças bem pequenas e crianças pequenas, que são: conviver, brincar (em diferentes espaços e tempos), participar (da escolha das brincadeiras, materiais e ambientes onde se quer estar), explorar, expressar e conhecer-se. Estrutura-se em torno de cinco campos de experiências: $O$ eu, o outro e o nós; Corpo, gestos e movimentos; Traços, sons, cores e formas; Escuta, fala, pensamento e imaginação e Espaços, tempos, quantidades, relações e transformações. Na BNCC, o termo bebê(s) aparece 13 vezes, contudo, em 12 delas, o uso do termo se volta unicamente para especificar as idades: bebê, criança bem pequena e criança pequena, no que diz respeito aos objetivos de aprendizagem e desenvolvimento específicos para cada uma, dentro dos cinco campos de experiência. A única vez que o termo aparece no corpo da BNCC para trazer uma orientação é no tocante à indissociabilidade entre o cuidar e educar, dizendo que a educação dos bebês e das crianças bem pequenas envolve aprendizagens muito próximas às do convívio familiar, como autonomia, socialização e comunicação, sem referência expressa à questão do espaço.

Com relação aos espaços para os bebês, duas vezes o documento faz menção à questão. Na primeira vez, dentro do campo de experiência $O$ eu, o outro e o nós, sob o código EI01EO03, apresenta-se como objetivo de aprendizagem e desenvolvimento para os bebês, "Interagir com crianças da mesma faixa etária e adultos ao explorar espaços, materiais, objetos, brinquedos" (BRASIL, 2018, p. 45), portanto, com destaque à dimensão relacional do espaço, o que demanda uma dimensão física adequada (FORNEIRO, 1998) e evoca a necessidade de organização e planejamento do uso do espaço como currículo (FORNEIRO, 1998; CAMPOS DE CARVALHO; RUBIANO, 2010; TUSSI, 2011). Em uma segunda citação, dentro do campo de experiência Espaço, tempo, quantidades, relações e transformações, o objetivo de aprendizagem e desenvolvimento para os bebês, sob o código EI01ET04 indica: "Manipular, experimentar, arrumar e explorar o espaço por meio de experiências de deslocamentos de si e dos objetos" (BRASIL, 2018, p. 51). Além dos aspectos já salientados, destacamos aqui a alusão a deslocamentos de si e dos objetos, que pressupõe a possibilidade de mobilidade dos bebês pelo espaço escolar (FARIA, 2000; SITTA, 2008; GOBBATO, 2011; HORN, 2014; SOARES; FLORES, 2017; FOCHI, 2018).

Desse modo, dos nove documentos analisados pela pesquisa, cinco deles fizeram menção aos espaços dos bebês de forma específica: Parâmetros Nacionais para a Qualidade da Educação Infantil - Volume 1 (BRASIL, 2006b) e Volume 2 (BRASIL, 2006c); Critérios para 
atendimento em creches que respeitem os direitos fundamentais da criança (BRASIL, 2009b); Brinquedos e Brincadeiras de Creches - Manual de Orientação Pedagógica (2012a) e a Base Nacional Comum Curricular (2018). Merece destaque os Critérios para atendimento (BRASIL, 2009b), o Manual de Orientação Pedagógica para as Creches (BRASIL, 2012a) e a BNCC (BRASIL, 2018).

Podemos perceber, sobretudo, dois pontos de convergência ao tratar dos espaços dos bebês na creche: primeiro, a necessidade de organização e planejamento do espaço, de forma articulada à organização e ao planejamento do tempo e dos agrupamentos e, segundo, a garantia do direito aos bebês de acessarem os diferentes espaços da creche, de entrarem em contato com a natureza, com destaque à importância dos espaços externos, de modo que possam ampliar seu repertório de conhecimentos sobre o mundo, com seus pares e adultos.

\section{CONSIDERAÇÕES FINAIS}

A análise dos documentos do MEC, selecionados para este estudo, sinaliza a visibilidade da temática dos espaços dos bebês na creche, ainda que haja um longo caminho a ser percorrido. Não podemos dizer que houve um crescimento da presença dos bebês, tratados de forma específica, nos documentos investigados, mesmo porque o aparecimento ou não do termo nesses documentos não foi constante nem aumentou no decorrer do período analisado - conforme dados apresentados no Quadro 1. Contudo, é importante destacar que três documentos merecem atenção especial: Critérios para atendimento em creches (BRASIL, 2009b), Brinquedos e Brincadeiras de Creche (BRASIL, 2012a) e a BNCC (BRASIL, 2018). Os dois primeiros (BRASIL, 2009b, BRASIL, 2012a) devido à proeminência dada às especificidades dos bebês e a $B N C C$ (BRASIL, 2018), por seu potencial de influência ao se configurar como a base para a construção dos currículos tanto estaduais quanto municipais, trazendo a expectativa de um tratamento mais apurado para os objetivos de aprendizagem e desenvolvimento específicos dos bebês, e por consequência, também dos seus espaços na creche. As ausências e os destaques dados aos bebês nos documentos analisados nos convidam a pensar: no decorrer dos próximos anos haverá, afinal, um crescimento do olhar para as especificidades da educação dos bebês nos documentos oficiais brasileiros e no cotidiano das creches?

Para que tal crescimento ocorra, entendemos que se faz necessário a continuidade e o adensamento dos estudos e pesquisas sobre as questões pedagógicas e curriculares relativas aos bebês, investigações que se voltem à questão dos espaços para essa faixa etária, sobretudo, aos 
espaços externos, visto que a visibilidade dos bebês é ainda menor nesses, conforme indicam as produções científicas mais recentes citadas ao longo do artigo.

No tocante ao trabalho cotidiano da creche, entendemos ser também necessária a intensificação dos diálogos com os professores, gestores e toda a comunidade escolar sobre a temática dos espaços dos bebês, que muitas vezes ficam a maior parte do tempo nos espaços internos/fechados das instituições, em nome da (in)segurança. Afinal, quando as menções aos bebês, aos espaços na EI ou aos espaços para os bebês se fazem presentes nos documentos oficiais do Ministério da Educação, elas carregam o potencial de provocar a comunidade escolar a assumir responsabilidades no tocante a: $(i)$ prover a estrutura física e relacional dos espaços; (ii)repensar as concepções sobre bebês, crianças, infância e espaços; (iii) refletir acerca do papel de cada profissional na educação infantil; (iv) identificar concepções, crenças e valores subjacentes às práticas desenvolvidas junto aos bebês nos espaços da creche e revê-las à luz das contribuições teóricas e resultados das pesquisas sobre a infância, a aprendizagem e o desenvolvimento dos bebês; $(v)$ organizar e reorganizar os espaços, os tempos e os agrupamentos; ( $v i$ ) planejar e mediar diferentes atividades tanto para os espaços internos quanto para os externos das salas dos bebês, ocupando corredores, pátios, parques e outras possibilidades existentes e passíveis de serem criadas, de modo que os bebês possam interagir com o que lhes é proposto, aprender e se desenvolver por meio da expansão de sua atividade no mundo, dentre outras responsabilidades. Entendemos que a questão do espaço que "educa" os bebês e os educadores é indissociável da questão de que educadores e bebês ao interagirem também podem "educar" o espaço (SITTA, 2008), o que se configura como perspectiva transformadora a ser, mais e mais, vivenciada nas creches.

Por fim, compreendemos ser necessária, efetivamente, uma política de Estado para a EI, que contemple as especificidades das crianças de 0 a 18 meses, o que demanda além do apoio à pesquisa científica, investimentos na formação continuada e em serviço dos professores e de toda a comunidade educativa que atua com esta faixa etária bem como dotação orçamentária que permita à gestão escolar contínuo incremento e melhoria em todas as dimensões dos espaços da creche.

\section{REFERÊNCIAS}

ALVES, I. L. Bebês, por entre vivências, afordâncias e territorialidades infantis: de como o berçário se transforma em lugar. Dissertação de Mestrado. Programa de Pós-Graduação em 
Educação. Universidade Federal do Mato Grosso/MT: 2013. Disponível em: <https://www1.ufmt.br/ufmt/unidade/userfiles/publicacoes/84e29fcb649847cb56213b4540c8a4c a.pdf>. Acesso em: 09 fev. 2019.

BARBOSA, M. C. S. As especificidades da ação pedagógica com os bebês. 2010. Disponível em: http://portal.mec.gov.br/docman/dezembro-2010-pdf/7154-2-2-artigo-mec-acao-pedagogicabebes-m-carmem/file. Acesso em: 31 Jul. 2019.

BARBOSA, M. C. S; RICHTER, S. R.S. Desenvolvimento da criança de 0 a 3 anos: Qual o currículo para os bebês e crianças bem pequenas? Programa Salto para o Futuro: Educação de crianças em creches. Ano XIX, n 15, out. 2009.

BARDIN, L. Análise de Conteúdo. São Paulo: Edições 70, 2007.

BARROS, M. I. A. de. Desemparedamento da infância: a escola como lugar de encontro com a natureza. 2ed. Criança e Natureza. Instituto Alana: Rio de Janeiro, 2018.

BRASIL. Base Nacional Comum Curricular. Educação Infantil. Brasília. MEC. SEB. 2018.

. Brinquedos e Brincadeiras de Creche - Manual de Orientação Pedagógica. MEC. SEB, 2012a.

. Constituição da República Federativa do Brasil. Brasília. Senado Federal, 1988.

Critérios para um Atendimento em Creches que Respeite os Direitos

Fundamentais das Crianças. Brasília: MEC. SEB, 2009b. 2009a.

Diretrizes Curriculares Nacionais para a Educação Infantil. Brasília. MEC. SEB,

Educação Infantil: subsídios para a construção de uma sistemática de avaliação. Brasília: MEC. SEB. Grupo de Trabalho de Avaliação da Educação Infantil. 2012b. Disponível em: http://portal.mec.gov.br/index.php?option=com_docman\&view=download\&alias=11990educacao-infantil-sitematica-avaliacao-pdf\&Itemid=30192. Acesso em: 16 Jun. 2019.

Lei 9394 de 20 de dezembro de 1996. Lei de Diretrizes e Bases da Educação Nacional. Brasília. Casa Civil, 1996.

. Parâmetros Básicos de Infraestrutura para Instituições de Educação Infantil. MEC.SEB. Brasília/DF: 2006d.

. Parâmetros Nacionais de Qualidade para a Educação Infantil. Volume 1. Brasília. MEC. SEB, 2006b.

Parâmetros Nacionais de Qualidade para a Educação Infantil. Volume 2. Brasília. MEC. SEB, 2006c.

Política Nacional de Educação Infantil: Pelo Direito das Crianças de 0 a 6 anos à educação. MEC. SEB. Brasília/DF: 2006a.

Revista Interinstitucional Artes de Educar. Rio de Janeiro, V. 6, N.2- pág. 556-577 maio-agosto de 2020: "Bebês e crianças: cultura, linguagem e políticas" 
BRASIL, M. G. de P. Espaço(s) na educação infantil: entre políticas e práticas. Tese de Doutorado. Programa de Pós-Graduação em Educação. Universidade Estadual do Rio de Janeiro/RJ: 2016. Disponível em: <https://docplayer.com.br/42400219-Maria-ghisleny-de-paivabrasil-espaco-s-na-educacao-infantil-entre-politicas-e-praticas.html>. Acesso em: 09 fev. 2019.

BROWN, D. O brincar, o pátio de recreio e a cultura da infância. In: MOYLES, J. R. A excelência do brincar. Porto Alegre: Artmed, 2006, p. 63-79.

CAMPOS DE CARVALHO, M, I.; RUBIANO, M. R. B. Organização do Espaço em Instituições Pré-escolares. In: OLIVEIRA, Z. de M. R. de. Educação Infantil: muitos olhares. São Paulo: Cortez, 2010.

CORSARO, W. A. Sociologia da infância. 2ed. Porto Alegre: Artmed, 2011.

FARIA, A. L. G. de. O espaço físico como um dos elementos fundamentais para uma pedagogia da educação infantil. In: FARIA, A. L. G. de; PALHARES, M. (Org.). Educação infantil pós LDB. Campinas: Autores Associados, 2000, p. 67-97.

FOCHI, P. (Org). O brincar heurístico na creche: percursos pedagógicos no observatório da cultura infantil - OBECI. Porto Alegre: Paulo Fochi Estudos Pedagógicos, 2018.

FORNEIRO, L. I. A organização dos espaços na educação infantil. In: ZABALZA, M. A. Qualidade em Educação Infantil. Porto Alegre: Artmed, 1998.

GOBBATO, C. Os bebês estão por todos os espaços!: um estudo sobre a educação de bebês nos diferentes contextos de vida coletiva da educação infantil. Dissertação de Mestrado. Programa de Pós-Graduação em Educação. Universidade Federal do Rio Grande do Sul/RS: 2011. Disponível em: https://lume.ufrgs.br/bitstream/handle/10183/29947/000778517.pdf?sequence=1\&isAllowed=y. Acesso em: 30 Abr. 2019.

HORN, M. da G. S. O bebê e suas relações com o espaço. In: CAIRUGA, R. R.; CASTRO, M. C. de (Orgs.). Bebês na escola: observação, sensibilidade e experiências essenciais. Porto Alegre: Mediação, 2015.

HORN, M. da G. S. Sabores, cores, sons, aromas: A organização dos espaços na Educação Infantil. Porto Alegre: Artmed, 2004.

LIMA, J. M.; MOREIRA, T. A.; LIMA, M. R. C. de. A sociologia da infância e a educação infantil: outro olhar para as crianças e suas culturas. Revista Contrapontos - Eletrônica, Vol. 14, N. 1, Jan-Abr. 2014.

LIMA, M. S. A cidade e a criança. São Paulo: Nobel, 1989.

LIMA, T. C.T. de; MIOTO, R. C. T. Procedimentos metodológicos na construção do conhecimento científico: a pesquisa bibliográfica. Revista Katálisis, v.10, Número especial, Florianópolis, p. 37-45, 2007. Disponível em:

<http://www.redalyc.org/articulo.oa?id=179613967004>. Acesso em 05 Out. 2019.

Revista Interinstitucional Artes de Educar. Rio de Janeiro, V. 6, N.2- pág. 556-577 maio-agosto de 2020: "Bebês e crianças: cultura, linguagem e políticas" 
RAMOS, T. K.G. A criança em interação social no berçário da creche e suas interfaces com a organização do ambiente pedagógico. Tese de Doutorado. Universidade Federal de Pernambuco/CE, Pós-Graduação em Educação, 2010.

SALVADOR, A. D. Métodos e técnicas de pesquisa bibliográfica. Porto Alegre: Sulina, 1986.

SARMENTO, M. J. A globalização e a infância: impactos na condição social e na escolaridade. In: GARCIA, Regina Leite; LEITE FILHO, Aristeo (Org.). Em defesa da educação infantil. Rio de Janeiro: DP\&A, 2001.

As culturas da infância nas Encruzilhadas da Segunda Modernidade. In: SARMENTO, M. J.; CERISARA, A. B. Crianças e Miúdos: perspectivas sociopedagógicas da infância e educação. Porto: Asa, 2004, p. 9-34.

SÁ-SILVA, J. R.; ALMEIDA, C. D. de; GUINDANI, J. F. Pesquisa documental: pistas teóricas e metodológicas. Revista Brasileira de História \& Ciências Sociais. Rio Grande, ano I, número I, jul.2009. Disponível em: https://www.rbhcs.com/rbhcs/article/view/6. Acesso em: 10 out. 2019.

SCHORN, A. A. L. O cotidiano na educação infantil: espaços, tempos, ações e o lugar dos bebês. Dissertação de Mestrado. Programa de Pós-Graduação em Educação. Universidade Federal de Santa Maria/RS: 2018. Disponível em: <https://repositorio.ufsm.br/handle/1/15478>. Acesso em: 09 fev. 2019.

SILVA, V. dos R. O que pensam as educadoras e o que revelam os bebês sobre a organização dos espaços na educação infantil. Dissertação de Mestrado. Universidade Federal de Sergipe. Programa de Pós-Graduação em Educação. São Cristóvão/SE: 2018. Disponível em: <http://ri.ufs.br/jspui/handle/riufs/9002>. Acesso em: 27 mar. 2019.

SIMIANO, L. P. Meu quintal é maior que o mundo... Da configuração do espaço da creche à constituição de um lugar para os bebês. Dissertação de Mestrado. Programa de Pós-Graduação em Educação. Universidade do Sul de Santa Catarina/SC: 2010. Disponível em: $<$ https://docplayer.com.br/34857018-Meu-quintal-e-maior-que-o-mundo.html>. Acesso em: 09 fev. 2019.

SINGULANI, R. A. D. As crianças gostam de tudo-o-que-não-pode: crianças em novas relações com a monitora e a cultura no espaço da creche. Dissertação de Mestrado. Programa de Pós-Graduação em Educação. Universidade Estadual Paulista. Marília/SP: 2009. Disponível em: $<$ https://www.marilia.unesp.br/Home/Pos-

Graduacao/Educacao/Dissertacoes/singulani_rad_me_mar.pdf>. Acesso em: 09 fev. 2019.

SITTA, K. F. Possibilidades de mediação dos espaços nas brincadeiras e aprendizagem das crianças na educação infantil. Dissertação de Mestrado. Universidade Federal de São Carlos, 2008.

SOARES, G. R; FLORES, M. L. R. "Desemparedar” na educação infantil: o que dizem a literatura e os documentos curriculares nacionais sobre o uso das áreas externas. In: ALBUQUERQUE, S. S. de; FELIPE, J.; CORSO, L. V. (Orgs). Para pensar a Educação 
infantil em tempos de retrocessos: lutamos pela educação infantil. Porto Alegre: Evangraf, 2017, p. 100-115.

TIRIBA, L. Educar e cuidar: buscando a teoria para compreender discursos e práticas. In: KRAMER, S. (Org.). Profissionais de Educação Infantil: gestão e formação. Rio de Janeiro: Ática, 2005.

TONUCCI, F. Quando as crianças dizem: agora chega! Porto Alegre: ArtMed, 2005.

TUAN, Y-Fu. Espaço e lugar. São Paulo: Difel, 1983.

Espaço e Lugar: a perspectiva da experiência. Tradução de Lívia de Oliveira. Londrina: EDUEL, 2013.

TUSSI, D. O espaço e o currículo: conexões e diálogos sobre as práticas pedagógicas no cotidiano da educação infantil. Dissertação de Mestrado. Universidade Federal de Santa Maria. Centro de Educação. Programa de Pós-Graduação em Educação, Santa Maria/RS: 2011. Disponível em: <http://repositorio.ufsm.br/handle/1/6982>. Acesso em: 30 abr. 2019.

ZABALZA, M. A. Qualidade em Educação Infantil. Porto Alegre: Artmed, 1998.

\footnotetext{
' Giseli Alcassas Masson. Mestre em Educação pelo Programa de Pós-Graduação em Educação da Universidade Federal de São Carlos (UFSCar). Professora e Formadora de Professores de Bebês na Rede Municipal de São José do Rio Preto. E-mail: g.alcassas@ gmail.com São José do Rio Preto-SP; ORCID: https://orcid.org/0000-0003-3020$\underline{789 X}$

ii Jarina Rodrigues Fernandes. Doutora em Educação pelo Programa de Pós-Graduação Educação: Currículo da Pontifícia Universidade Católica de São Paulo (PUC-SP). Professora do Departamento de Teorias e Práticas Pedagógicas e Programa de Pós-Graduação em Educação da Universidade Federal de São Carlos (UFSCar). E-mail: jarina.fernandes@ufscar.br São Carlos-SP; ORCID: https://orcid.org/0000-0001-8028-467X
}

\footnotetext{
iii A Base Nacional Comum Curricular (BRASIL, 2018) considera Bebês a idade compreendida entre 0 a 1 ano e 6 meses, considera Crianças bem pequenas de 1 ano e 7 meses a 3 anos e 11 meses e Crianças pequenas de 4 anos a 5 anos e 11 meses. O documento Brinquedos e Brincadeiras de Creche (BRASIL, 2012a) considera Bebês de 0 a 1 ano e meio e Crianças Pequenas de 1 ano e meio a 3 anos e 11 meses.

iv A idade a ser atendida pela Educação Infantil passou para 0 a 5 anos somente após a Lei 12.796 de 4 de abril de 2013.

v Neste estudo, são focalizados os documentos publicados pós LDB (1996). O documento citado é de 1995, anterior à LDB, tendo sido reimpresso em 2009. Como é um documento importante para a análise da temática, merecendo fazer parte do estudo, foi citado considerando-se o ano de sua reimpressão.
}

Revista Interinstitucional Artes de Educar. Rio de Janeiro, V. 6, N.2- pág. 556-577 maio-agosto de 2020: "Bebês e crianças: cultura, linguagem e políticas"

DOI: 10.12957/riae.2020.45958 